\title{
REQUALIFICAÇÃO DE VAZIOS URBANOS SOB A ÓTICA DA PRESERVAÇÃO E DO DESENVOLVIMENTO
}

\author{
Requalification of voids urban from the perspectiv of preservation \\ and of development
}

\section{Wanderson Schmidt Amaral}

Faculdade Cesumar de Curitiba (PR, Brasil). Centro de Ciências Exatas, Tecnológicas e Agrárias. Acadêmico do curso de Arquitetura e Urbanismo. Bolsista PIC/CNPq-UniCesumar. E-mail: wandersonschmidt.arquitetura@gmail.com.

\section{Analu Cadore}

Faculdade Cesumar de Curitiba (PR, Brasil). Centro de Ciências Exatas, Tecnológicas e Agrárias. Docente do curso de Arquitetura e Urbanismo. Mestre em Urbanismo e História da Cidade - PGAU UFSC. E-mail: analucadore@gmail.com.

\section{Resumo}

Ações de reabilitação em áreas centrais urbanas através da ocupação de vazios e estruturas ociosas têm permeado as discussões sobre preservação do patrimônio arquitetônico histórico das grandes cidades. Muitas abordagens ocorrem no sentido da preservação patrimonial e desenvolvimento urbano serem encarados como antagônicos em algumas ações que almejem o progresso municipal. O presente trabalho tem como objetivo compreender como a requalificação de vazios urbanos, geralmente ligados às áreas de valor histórico, pode contribuir para a preservação da memória urbana e para o desenvolvimento da cidade. A observação de posturas adotadas, tanto em Curitiba como em outras cidades, bem como a revisão bibliográfica de estudos realizados nestes locais, contribuiu para a formação de um cabedal teórico que consiste na base desta produção acadêmica. Verifica-se que a gestão da cidade é uma atividade complexa, todas as ações preservacionistas - sejam elas de cunho histórico ou técnico - esbarram na figura do poder público e suas esferas de atuação política. Observa-se também que os desafios não se apresentam apenas no que compete a restauração física do patrimônio e estruturas obsoletas, mas também à articulação entre políticas urbanas que empreguem a ressignificação das mesmas, promovendo apropriação e diversidades de uso nas áreas de interesse.

Palavras-Chave: Vazios urbanos. Preservação. Desenvolvimento urbano.

\section{Abstract}

The rehabilitation actions of urban central are as throught he occupation of urban voids and residual spaces are permeated through discussions about preservation of the historical architectural heritage of the big cities. Many approaches occur in the sense that heritage preservation and urban development can be seen as antagonistic in some actions that aim at municipal progress. Through a technical approach, this work aims to understand how there qualification of urban voids, generally linked to are as of heritage interest for their historical value, can contribute to the preservation of urban memory and the development of the city. The observation of the positions adopted in this sense, both in Curitiba and in other cities, as well as the bibliographic review of scientific articles, books and publications of studies carried out in these places, contributed to the formation of a theoretical base that is the base of this academic production. It is verified that the management of the city is a complex activity, all the preservation actions - be they of historical or technical character - run up against the figure of the public power and its spheres of political action. It is also observed that the challenges are presented not only in what concerns the physical restoration of patrimony and obsolete structures, but also the articulation between urban policies that employ there-signification of the same, promoting appropriation and diversities of use in the areas of interest.

Keywords: Urban voids. Preservation. Urban development. 


\section{Sumário}

1. Introdução; 2. Materiais e métodos; 3. Desenvolvimento urbano; 3.1 Desenvolvimento urbano no Brasil; 3.2 Desenvolvimento urbano em Curitiba; 4. Patrimônio e políticas de preservação; 4.1 Patrimônio no Brasil; 4.2 Políticas de preservação em Curitiba; 5. Requalificação de vazios e lógicas de ocupação; 6 . Considerações finais; Referências

\section{INTRODUÇÃO}

Projetos de requalificação de vazios urbanos têm conquistado grande olhar do Poder Público-Privado através iniciativas que buscam valorizar políticas de ocupação como mecanismos de desenvolvimento urbano e transformação da imagem da cidade. Contudo, enquanto algumas áreas são preservadas devido seu apelo sociocultural, outras que estão localizadas às margens dos grandes centros que muito sofreram com a degradação, abandono e marginalização, sofrem hoje com a pressão especulativa por conta de sua localização.

Curitiba atualmente é considerada um dos maiores centros urbanos no Brasil, foi mundialmente conhecida por suas inovações no âmbito do planejamento e desenvolvimento urbanístico, embora hoje apresente diversas áreas subutilizadas que poderiam ser requalificadas a fim de promover novos usos. Neste sentido, observa-se como ocorreram as políticas de gestão voltadas a instrumentos de preservação no projeto Novo Centro em 2009, a fim de compreender como a ocupação e requalificação de Vazios Urbanos no Centro Histórico pode contribuir para a preservação do patrimônio histórico e do desenvolvimento urbano através da diversidade de usos (JACOBS, 1961).

A produção deste material visa contribuir com a esfera social estimulando a apropriação cultural e ressignificação dos bens históricos, e também com a esfera científica, a partir da difusão dos estudos no cenário urbano.

\section{MATERIAIS E MÉTODOS}

O ponto de partida desta pesquisa tem como principal procedimento técnico, a observação e análise de situação concreta. A interpretação de estudos realizados acerca do tema proposto, contribuiu para o embasamento teórico que consiste como apoio desta produção acadêmica.

Para que tal objetivo fosse atingido, elencou-se as seguintes etapas: investigar as políticas de preservação patrimonial em Curitiba; comparar a revitalização de vazios urbanos na capital com casos que se conectam por uma lógica de preservação; relacionar o desenvolvimento urbano com a preservação das regiões patrimoniais, considerando em resposta ao problema de pesquisa, validar ou refutar a hipótese inicial.

\section{DESENVOLVIMENTO URBANO}

\subsection{DESENVOLVIMENTO URBANO NO BRASIL}

O desenvolvimento urbano é o produto do planejamento, regulação e controle dos instrumentos de progresso de um território já urbanizado, ou seja, assume caráter qualitativo ao implicar na maneira como o território urbano progride e não o quanto cresce.

O desenvolvimento urbano no Brasil é amparado por ferramentas de gestão como a 
Lei 10.257/2001, conhecida como Estatuto da Cidade, e pela Política Nacional de Desenvolvimento Urbano, que consiste em um conjunto de diretrizes estabelecidas a partir da $1^{\circ}$ Conferência Nacional das Cidades (2003).

As diretrizes estabelecidas pelo Estatuto da Cidade são dispostas sobre políticas que possam colocá-las em prática, dentre estas políticas estão os planos diretores. O ato de planejar é fundamental e necessário. Planejar, sob qualquer ótica que
se deseje analisar, tem como fim traçar um caminho para o futuro, buscando
prever possíveis dificuldades e traçar possibilidade de solucionar os problemas
porventura apresentados. Desse modo, o planejamento urbano também deve
ter a preocupação de perceber o espaço social nas suas dimensões econômica,
política e cultural, a fim de se tornar o mais efetivo e concreto. (FONSECA,
2009, p. 52).

\subsection{DESENVOLVIMENTO URBANO EM CURITIBA}

O planejamento urbano em Curitiba teve início em 1943, sendo elaborado um plano urbanístico que incluía medidas de saneamento básico e reestruturação viária, definição de áreas para habitação, serviços e indústrias. Através do plano diretor municipal estabeleceu uma hierarquia para as ruas sendo pioneira na implantação de calçadões que limitam o uso do automóvel.

Desde os primeiros planos diretores já eram previstas políticas de revitalizações e preservações na área central da Capital. Consolidou-se como modelo de intervenção em grandes centros, tornando se referência mundial, segundo o Instituto de Pesquisa e Planejamento Urbano de Curitiba - IPPUC, fruto de um processo técnico criativo, indispensável ao desenvolvimento ordenado, que articula o desenvolvimento urbano a implantação de espaços públicos, preservação do patrimônio histórico, qualidade de transporte e preocupação com o meio ambiente.

Como parâmetros de desenvolvimento, Curitiba possui uma população estimada de 1.908.359 (IBGE, 2017), PIB de 44.624,32 per capita, contra uma média nacional de 28.876,00 (IBGE, 2015). A cidade já foi apontada como a capital brasileira com o melhor Índice de Desenvolvimento da Educação Básica (6,3) (IDEB, 2015) e o menor índice de analfabetismo, sendo também apontada como número um na educação nacional entre as capitais, e uma das cinco melhores cidades para investir na América Latina.

\section{PATRIMÔNIO E POLÍTICAS DE PRESERVAÇÃO}

\subsection{PATRIMÔNIO NO BRASIL}

O patrimônio trata-se de bens materiais ou naturais que possuem importância na história de determinada sociedade ou comunidade. Refere-se a um acervo que caracteriza o patrimônio cultural de um povo ou nação, conceito disseminado a partir do século XIX após a Revolução Francesa (1789). Nesta lógica o patrimônio histórico cultural tangível ou material é reconhecido como produto da humanidade, expandido a produção de bens móveis e imóveis, alvos de museus e sítios arqueológicos.

Observa-se que um patrimônio não precisa ser necessariamente reconhecido por algum órgão para caracterizar um bem de valor cultural para uma comunidade. O reconheci- 
mento e valor atribuído ao patrimônio depende da memória coletiva, sendo ela imprescindível para os processos de preservação.

O Brasil se manteve avançado em políticas públicas de preservação, há cerca de 80 anos foi instituído a figura jurídica do tombamento em nosso país por meio do Decreto-Lei ${ }^{\circ}$ 259 (1937), estabelecendo-se também, o Serviço do Patrimônio Histórico e Artístico Nacional - SPHAN, atual IPHAN (Instituto do Patrimônio Histórico e Artístico Nacional). A partir da manifestação no interesse de preservação às futuras gerações, entram em ação política de salvaguarda por meio do apoio e supervisão dos órgãos municipais, estaduais e nacionais.

\subsection{POLÍTICAS DE PRESERVAÇÃO EM CURITIBA}

Curitiba foi considerada nas últimas quatro décadas modelo de planejamento urbano, o que a tornou referência mundial com a criação de um Setor Histórico, foi a primeira política de preservação da capital instituída como diretriz no Plano Diretor de 1965 e formalizada pelo decreto $n^{\circ} 1.160$ de 1971 que delimitou a área do Setor. A delimitação de um centro histórico inseriu Curitiba no que é reconhecido como indústria cultural (CHOAY, 2001). No mesmo ano foi iniciado as obras do processo de valorização urbanística e cultural da cidade, projeto coordenado por Cyro Correa Lyra sob a gestão do prefeito e urbanista Jaime Lerner.

Em 14 de dezembro de 1979, foi criado o decreto $n^{\circ} 1.547$, que baseado no decreto $\mathrm{n}^{\circ} 1.160$, designou os imóveis que integrariam o Setor Especial, estabelecendo as UIPs (Unidades de Interesse de Preservação).

No ano 2000, foi estabelecida mais um importante instrumento de apoio a preservação, a criação da Lei $n^{\circ}$ 9.803, designa que os proprietários de imóveis considerados UIPs que não puderem cumprir com as leis de preservação do patrimônio histórico, mediante uma prévia autorização do poder municipal, podem transferir parcial ou totalmente o potencial não utilizável desse imóvel, sendo ressarcido de acordo com as disposições legais.

Para a viabilização econômica da conservação patrimonial conforme os dispositivos municipais, a prefeitura propõe a redução de impostos aos proprietários de edifícios considerados de interesse à memória urbana através da lei complementar de 40/01.

\section{REQUALIFICAÇÃO DE VAZIOS E LÓGICAS DE OCUPAÇÃO}

Curitiba conquistou uma grande projeção nacional e internacional como "cidade modelo", título adotado nas estratégias de marketing pautada nas reformas urbanas durante seu período de estruturação.

Em 2009, o Centro Histórico receberia um novo olhar do poder público, a fim de valorizar a imagem da região a gestão municipal anunciou o projeto Novo Centro como medida de requalificação dos vazios urbanos na área central (CRESTANI, 2015).

Uma das vias elencadas a receber o novo projeto foi a Rua Riachuelo, que segundo Crestani (2015) foi a primeira via urbana a congregar atividades comerciais na capital. $\mathrm{Na}$ década de 1990, a rua foi definida como local de risco, com práticas recorrentes de prostituição e consumo de entorpecentes, fenômeno que para Fernandes (2010) atuaram como atores de degradação na região. 
Para o projeto Novo Centro, a gestão baseou-se em projetos de revitalizações anteriores, como a rua XV de Novembro, tombada no ano de 1974, também pertencente ao Centro Histórico e que foi transformada no primeiro calçadão de pedestres do Brasil. Atualmente a rua XV abriga edifícios históricos que exercem funções comerciais e financeiras, tendo sua arquitetura relativamente preservada, comprovando a importância do uso atrelado a preservação do patrimônio.

Através da mesma lógica de preservação compara-se o projeto Novo Centro com o projeto Nova Luz na cidade de São Paulo. Metrópole com aproximadamente 11 milhões de habitantes, marcada por uma dinâmica de construção e destruição em sua paisagem urbana (FRÚGOLI JR, 2009).

Presente na região central da cidade, o bairro da Luz, inaugurado em 1901 cujo marco histórico foi a Estação da Luz é marcado pela presença de edifícios culturais tombados, possui forte densidade urbana e social.

Dentre esses edifícios, o edifício que abriga a Pinacoteca de São Paulo foi recentemente reabilitado pelo arquiteto vencedor do Premio Pritzker, Paulo Mendes da Rocha. O projeto desencadeou a promoção de um novo fluxo de pessoas ligadas às classes médias e altas na região central da cidade, em uma área que sofria rechaço de apropriação por conta do comércio de drogas e prostituição, transformando a Luz em um bairro cultural (FRÚGOLI JR, 2009).

No final de 2005, a Prefeitura de São Paulo anunciou um programa de incentivo fiscal para o bairro, o objetivo foi atrair investimentos do setor privado e em torno de dois anos após o incentivo, ocorreram as primeiras demolições na região.

Segundo Mosqueira (2007), cabe destacar que o abandono no centro da cidade de São Paulo ocorreu pelo fato de se ter deixado deteriorar o estoque imobiliário e não por seu envelhecimento. A autora observa que não havia mais interesse em mantê-los, pois teriam perdido seu valor imobiliário.

Assim como ocorre em São Paulo, áreas como Centro Histórico de Curitiba possuem forte pressão especulativa por conta de sua localização. Tal fenômeno cria um alerta onde entende-se que ações de renovação podem prevalecer em relação a reabilitação. Grandes medidas de requalificação urbana em áreas de interesse histórico moldam preocupações quanto aos reais objetivos do poder público, já que todas as medidas de preservação esbarram em suas esferas de atuação política.

De acordo com a obra de Ribas e Bezerra (2012), conflito entre propriedade e bem coletivo está presente com muita força no cenário urbano. Em função do princípio da maximização "[...] os bens patrimoniais podem "impedir" o desenvolvimento da atividade econômica que norteia a lógica imobiliária, inibindo a argumentação favorável à preservação" (RIBAS; BEZERRA, 2012, p. 104).

Para que o sucesso de iniciativas públicas não sejam reféns do subsídio privado, é necessário que haja revisões constantes nas diretrizes uso e ocupação sob a gestão de uma esquipe capacitada, o que permite uma demanda correspondente à expectativa e também 
aos recursos necessários para viabilização de projetos, prevendo espaços de cultura e lazer.

A criação de espaços culturais em imóveis de valor histórico que se encontram desocupados possibilita o aumento da circulação de pessoas e, favorecidos pela diversidade de usos que possibilitam, promovem a recuperação de todo o entorno. Esta diversidade promove a vitalidade urbana (JACOBS, 1961), fundamental para o desenvolvimento de um ambiente público dinâmico e autossuficiente.

Entende-se que a requalificação de vazios urbanos prevendo equipamentos culturais, evita a substituição de edifícios importantes à memória urbana por novas estruturas.

A partir da iniciativa de requalificação de vazios na rua Riachuelo foi possível reabilitar antigas estruturas como o Antigo Quartel General, que hoje abriga um complexo cultural que resgata a tradição do cinema de rua em Curitiba, o Cine Passeio, localizado na rua Riachuelo $\mathrm{n}^{\circ} 410$, esquina com a rua Presidente Carlos Cavalcanti.

Segundo Mosqueira (2007), projetos que fomentem a participação popular geram não somente a reabilitação física e sim a reabilitação integral, incentivando a harmonia entre espaço urbano e tecido social.

Além disso, a ressignificação social, a apropriação cultural e a valorização espacial destas estruturas, são responsáveis por incrementar o desenvolvimento urbano através do aquecimento econômico local e da queda nos índices de violência.

\section{CONSIDERAÇÕES FINAIS}

$\mathrm{Na}$ presente pesquisa, foram abordados diversos tópicos para que fosse possível a melhor compreensão do tema proposto, apresentando em forma de descrição e discussão a partir do referencial teórico, o histórico de políticas de gestão urbanas voltadas a requalificação de vazios em áreas centrais.

Demonstrou-se, através das bibliografias utilizadas, como os vazios urbanos estão ligados a dinâmica urbana contemporânea, oportunizando um novo olhar às estruturas subutilizadas.

Foi possível entender que todas as políticas de preservação estão diretamente ligadas ao poder público, considerando o alerta sobre os interesses quando grandes reformas estão circundadas pelo investimento do setor imobiliário.

Para superar os fenômenos da especulação imobiliária, entende-se que não é possível pensar isoladamente o restauro como ferramenta de requalificação. A preservação plena só ocorre quando atinge influências sociais, ressignificando o espaço a partir do uso coletivo. A ação de restauração abrange tão somente à estrutura física do edifício, que contribui para a requalificação do espaço urbano circundante, mas não é a única responsável por todo o processo.

Vale ressaltar que a reciclagem de espaços ociosos é indispensável para o desenvolvimento urbano. Para tanto é necessária a revisão ampla das políticas públicas empregadas no plano diretor afim de promover ocupação de diversas naturezas. 
A apropriação de vazios a partir da diversidade de usos é responsável por gerar um fluxo dinâmico no espaço urbano, fenômeno responsável pela vitalidade, principal agente de preservação e desenvolvimento em grandes cidades.

Assim sendo, a requalificação de espaços vazios nas ações de recuperação de centros históricos degradados se mostra uma prática bastante profícua e que merece ser olhada com mais cuidado pelos órgãos públicos a fim de recuperar os espaços que já possuem grande significação e representam a identidade da população local.

\section{REFERÊNCIAS}

BRASIL. INSTITUTO BRASILEIRO DE GEOGRAFIA E ESTATÍSTICA. Produto Interno Bruto (PIB) Curitiba. Rio de Janeiro: IBGE, 2015. Disponível em: www.ibge.gov.br. Acesso em: 16 abr. 2018.

BRASIL. Lei $n^{\circ} 378$ de 3 de janeiro de 1937. Câmara dos Deputados: Disponível em: https://www2. camara.leg.br. Acesso em: 10 jan. 2006.

BRASIL. Lei no 10.257 de 10 de julho de 2001. Câmara dos Deputados: Disponível em: https://www2. camara.leg.br. Acesso em: 10 jan. 2006.

CHOAY, F. A Alegoria do patrimônio. Tradução Luciano Vieira Machado. São Paulo: Estação Liberdade/ Editora UNESP, 2001.

CRESTANI, A. M. Z. As faces (in)visíveis da regeneração urbana: rua Riachuelo e a produção de um cenário gentrificado. Cad. Metrop., São Paulo, v. 17, n. 33, p. 179-200. 2015.

CURITIBA. Decreto Municipal $n^{\circ} 1.160$, de 5 de agosto de 1971. Câmara Municipal de Curitiba. Disponível em: http://www.cmc.pr.gov.br/spl.htm. Acesso em: 15 jun. 2018.

CURITIBA. Decreto Municipal n 1.547, de 14 de dezembro de 1979. Câmara Municipal de Curitiba. Disponível em: http://www.cmc.pr.gov.br/spl.htm. Acesso em: 15 jun. 2018.

CURITIBA. Lei Municipal $\mathbf{n}^{\circ} \mathbf{9 . 8 0 3}$, de 3 de janeiro de 2000. Câmara Municipal de Curitiba. Disponível em: http://www.cmc.pr.gov.br/ spl.htm. Acesso em: 10 ago. 2018.

CURITIBA. Lei Municipal Complementar $\mathrm{n}^{\circ}$ 40, de 18 de dezembro de 2001. Câmara Municipal de Curitiba. Disponível em: http://www.cmc.pr.gov.br/ spl.htm. Acesso em: 10 ago. 2018.

FERNANDES, J. C. (2010). Riachuelo 407. Gazeta do Povo, setembro. Disponível em: gazetadopovo. com.br/vidaecidadania/conteudo.phtml?id=1026175\&tt=Riachuelo-407. Acesso em: 12 jul. 2018.

FONSECA, J. F. R. O Orçamento Participativo e a Gestão Democrática de Goiânia. 2009. Dissertação (Mestrado em Desenvolvimento e Planejamento Territorial) - Programa de Pós-Graduação em Desenvolvimento e Planejamento Territorial da Universidade Católica de Goiás, Goiânia, 2009.

FRÚGOLI JR., Heitor, SKLAIR. O bairro da Luz em São Paulo: questões antropológicas sobre o fenômeno da gentrification/ Cadernos de Antropologia Social, n. 30, p. 119-136, 2009.

INEP. IDEB - Índice de desenvolvimento da educação básica, 2005-2015. Disponível em: http://ideb. 
inep.gov.br. Acesso em: 16 abr. 2018.

JACOBS, J. Morte e Vida de Grandes Cidades. 3. ed. São Paulo: Martins Fontes, 2011.

MOSqUEIRA, Tatiana Meza. Reabilitação da região da Luz - Centro histórico de São Paulo: projetos urbanos e estratégias de intervenção. 2007. Dissertação (Mestrado em Planejamento Urbano e Regional) - Faculdade de Arquitetura e Urbanismo, Universidade de São Paulo, São Paulo, 2007. doi:10.11606/D.16.2007.tde-28052010-113207

RIBAS, O; BEZERRA, M. C. L. Políticas de Preservação e Desenvolvimento Urbano no Brasil: OCULUM ENSAIOS, Campinas, p. 100-107, jan/jun. 2012.

Recebido em: 15/06/2019

Aceito em: 18/12/2019 